\title{
Development of IDF-curves for tropical india by random cascade modeling
}

\section{A. Rana ${ }^{1}$, L. Bengtsson ${ }^{1}$, J. Olsson ${ }^{2}$, and V. Jothiprakash ${ }^{3}$}

${ }^{1}$ Department of Water Resources Engineering, Lund University, P.O. Box 118, Lund, 22100, Sweden

${ }^{2}$ Swedish Meteorological and Hydrological Institute, Norrköping, 60176, Sweden

${ }^{3}$ Department of Civil Engineering, IIT Bombay, Mumbai, 400 076, India

Received: 20 March 2013 - Accepted: 8 April 2013 - Published: 11 April 2013

Correspondence to: A. Rana (arunranain @gmail.com, arun.rana@tvrl.Ith.se)

Published by Copernicus Publications on behalf of the European Geosciences Union.

\section{IDF-curves for tropical india by random cascade modeling}

A. Rana et al.

\section{Title Page}

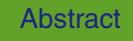

Introduction

Conclusions

References

Tables

Figures

14

$\rightarrow 1$

4

Back

Close 


\section{Abstract}

Efficient design of urban drainage systems is based on statistical analysis of past rainfall events at fine time scales. However, fine time scale rainfall data are usually lacking in many parts of the world. A possible way forward is to develop methods to derive 5 fine time scale rain intensities from daily observations. This paper applied cascadebased disaggregation modeling for generation of fine time scale rainfall data for Mumbai, India from daily rainfall data. These data were disaggregated to 10-min values. The model was used to disaggregate daily data for the period 1951-2004 and develop intensity-duration-frequency (IDF) relationships. This disaggregation technique is comused assuming scale-invariance using constant parameters. For the Mumt rains it was found better to use parameters dependent on time scale and rain volume. Very good agreement between modeled and observed disaggregation series was found for the time scales larger than $1 / 2 \mathrm{~h}$ for the 1/2-yr period when short term data were available. Although the parameters were allowed to change with time scale, the rain intensities of duration shorter than $1 / 2 \mathrm{~h}$ were overestimated. When IDF-curves had been established, they showed that the current design standard for Mumbai city, $25 \mathrm{~mm} \mathrm{~h}^{-1}$, has a return period of less than one year. Thus, annual recurring flooding problems in Mumbai appear evident.

\section{Introduction}

20 Extreme weather events have severe consequences for human society, e.g. emergency planning, engineering design, reservoir management, and pollution control. Risk calculations rely entirely on knowledge of the frequency of these extreme events (e.g. Kumke, 2001). Assessment of extreme precipitation events is an important part of hydrologic risk analysis and design. Evaluation of rainfall extremes, as embodied in intensity-duration-frequency (IDF) relationship, has long been a major focus of both theoretical and applied hydrology, Langousis and Veneziano (2007). Rainfall frequency

\section{HESSD}

10, 4709-4738, 2013

IDF-curves for tropical india by random cascade modeling

A. Rana et al.

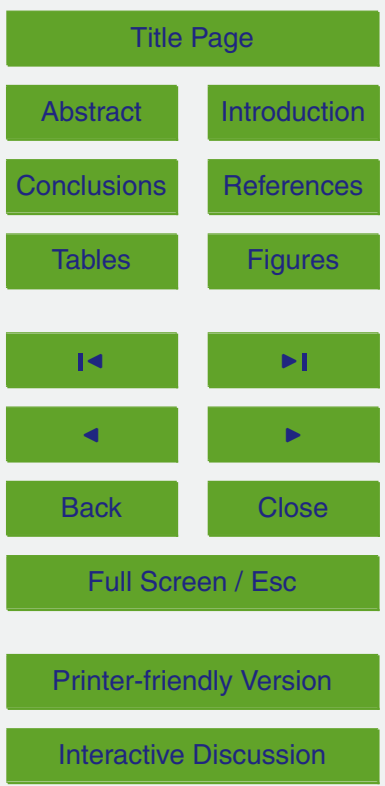


analyses are used extensively in the design of systems to handle storm water runoff, including roads, culverts and drainage systems among other uses.

Access to fine time scale rainfall data is of prime importance for IDF analysis. However, such data of considerable length are usually not available in most parts of the 5 world. A possible way forward is to develop necessary rainfall information from the commonly available daily rainfall data. Stochastic simulation tools can be used to extend historical data and generate new fine time scale data, which have similar statistical properties as the observed ones (Gaume et al., 2007). Stochastic disaggregation provides possibility of generating fine time scale rainfall data from coarser resolution.

10 Traditionally there have been two approaches for this. One approach is based on fitting theoretical probability distribution functions to precipitation variables (e.g. Hershenhorn and Woolhiser, 1987; Econopouly et al., 1990; Connolly et al., 1998). The other approach starts from rectangular pulse stochastic rainfall models and devise ways to use these for disaggregation (e.g. Bo et al., 1994; Glasbey et al., 1995; Cowpertwait et al., 15 1996).

An approach to model the statistical distribution of rainfall in time and space that has emerged during the latest decades is by random cascade processes, Schertzer and Lovejoy (1987), Over and Gupta (1994) and many more. Random cascade models are also used for downscaling of precipitation. A cascade process repeatedly divides the tity according to rules specified by the cascade generator. A generic feature of random cascades is a scaling behaviour, which generally may be defined as a relationship between statistical moments of various orders and a scale parameter. The applicability of scaling and cascade models to temporal rainfall has been demonstrated in a number of empirical data analyses (e.g. Hubert et al., 1993; Olsson, 1995; Harris et al., 1996; Svensson et al., 1996; Tessier et al., 1993; Menabde and Sivapalan, 2000; Molnar and Burlando, 2005; Rupp et al., 2009; Licznar et al., 2011). Encouraging results for spatio-temporal disaggregation of rainfall have been reported. Rupp et al. (2009)
HESSD

$10,4709-4738,2013$

IDF-curves for tropical india by random cascade modeling

A. Rana et al.

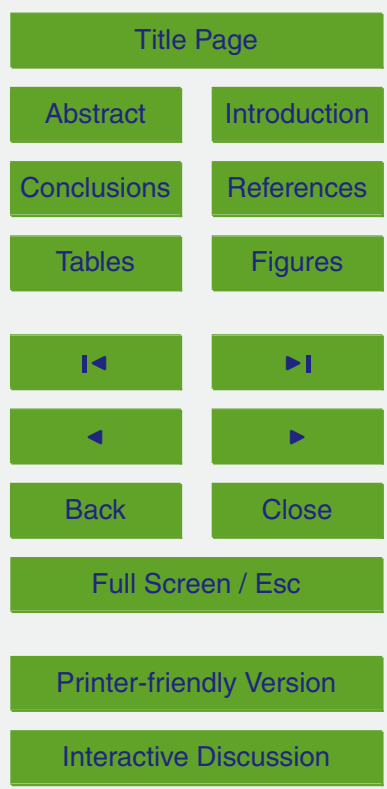


applied intensity- and time scale-dependent cascade models for disaggregating daily precipitation totals into hourly totals for the Christchurch Airport gauge in New Zealand.

The disaggregation studies performed to date have generally concerned model development, calibration, application and evaluation using extensive, high-resolution (time 5 and volume), high-quality precipitation data bases. In practice however available highresolution data for model calibration are often limited to data over short periods of data (e.g. from a measurement campaign) or data not always of the highest quality. Still, these kinds of data must be used in real-world applications supporting design of urban infrastructure. The Indian Meteorological Department (IMD) uses IDF relationships to 10 estimate rainfall frequency for durations of $5 \mathrm{~min}$ up to $24 \mathrm{~h}$. However, many stations do not have long data records for durations shorter than 1 day and therefore the character of short rainfall durations must be estimated from other sources.

In the present study the focus is on the Indian city of Mumbai (formerly called Bombay), which receives an average annual rainfall of $2142 \mathrm{~mm}$ with monsoon rainfall contributing for $96 \%$ of the total (Rana et al., 2012). During the monsoon period severe flooding occurs in many parts of the city. Potentially short term rainfall data could be used to improve the decision making process for various hydrological processes such as urban flooding mitigation. A random cascade model for disaggregation of daily rainfall to higher time resolution is employed, originally developed and fitted to rains in southern Sweden by Olsson (1998) and later used with data from British and Brazil stations, Güntner et al. (2001) and in semiarid areas of Tunisia by Jebari et al. (2012).

The key objectives of this study were to (1) test and apply the cascade-type disaggregation model to an area with very limited historical short-term observations. (2) Evaluate suitability and performance in a monsoon climate (India) and (3) assess the current
HESSD

10, 4709-4738, 2013

IDF-curves for tropical india by random cascade modeling

A. Rana et al.

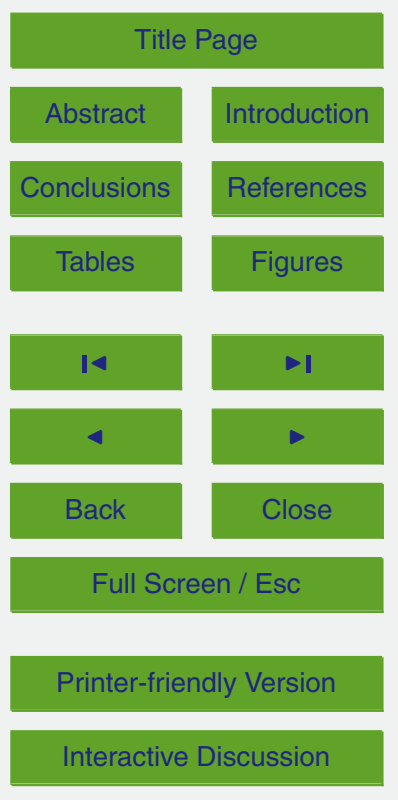




\section{Methodology}

\subsection{Study area and data base}

Daily accumulated rainfall data were obtained from the Indian Meteorological Department (IMD) for the period 1951-2004. The data were collected from IMD observa-

5 tory at Colaba station $\left(18^{\circ} 54^{\prime} \mathrm{N}, 72^{\circ} 49^{\prime} \mathrm{E}\right)$ in Mumbai which is situated at a height of $11 \mathrm{~m}$ a.s.l., the daily volume resolution is $0.1 \mathrm{~mm}$. There is no missing data. Reference is made to Rana et al. (2012) for details of rainfall characteristics in Mumbai. Fine time scale data of 10 min interval was obtained from the same observatory for a period of 6 months, July-December 2006. The rain was measured with a tipping-bucket with volume resolution of $0.25 \mathrm{~mm}$. The $2006 \mathrm{yr}$ data were used to calibrate and evaluate the rainfall disaggregation model, estimate parameters, and define settings to fit the observed data using scale-invariant properties of rainfall time series. Descriptive statistics of daily data for both the datasets i.e. 1951-2004 and July-December 2006 are given in Tables $1 \mathrm{a}$ and $1 \mathrm{~b}$. January-June is a rather dry period and most of the rainfall occurs in the latter part of the year, i.e. July-December. It can be noted from the table that July-December in 2006 is much wetter $(2170 \mathrm{~mm})$ than the overall period of 1951-2004 (1643 mm). The highest volume of precipitation for 10, 30 and 60 min duration is $18.3,24.1$ and $41.7 \mathrm{~mm}$. The more modest storms corresponding to 5 th largest values in the 6-months period of 2006 are shown in Table 1b: 13.2, 20.8 and $28.2 \mathrm{~mm}$ for durations $10,30,60 \mathrm{~min}$ and $76.9,117.0 \mathrm{~mm}$ for the longer durations of 12 and $24 \mathrm{~h}$.

\subsection{Disaggregation of daily rainfall}

When short-term data is not available for design, rain intensities of short duration may be found from other cities. Relations between annual or seasonal precipitations at the two cities can be used for establishing IDF curves for the city, as done for Danish cities by Madsen et al. (2009) and for Swedish cities by Dahlström (1979). Another way of estimating short-term rainfall from observations over longer periods is by temporal
IDF-curves for tropical india by random cascade modeling

A. Rana et al

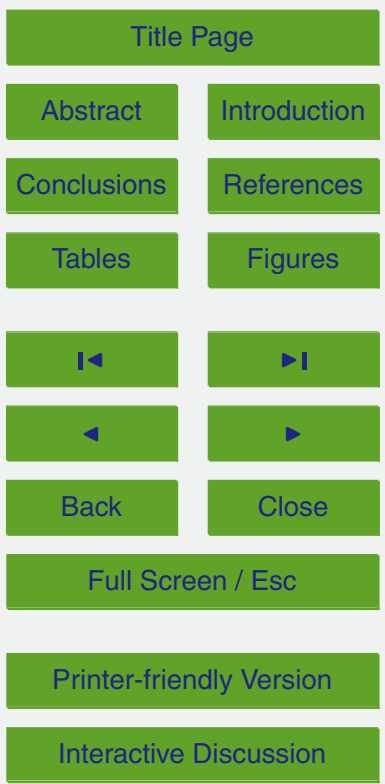


disaggregation. One approach along this line is to fit theoretical probability distributions to different rain characteristics (e.g. Tessier et al., 1993; Schertzer and Lovejoy, 1987 , etc). Another approach is cascade-based disaggregation, combining an underlying hypothesis of cascade-type scaling with empirically observed features of temporal 5 rainfall. The cascade-based disaggregation model for continuous rainfall time series used in this study is based on the principles suggested by Olsson (1998). Güntner et al. (2001) and Jebari et al. (2012) showed that the approach is applicable for cascading from 24 to $1 \mathrm{~h}$ duration in different climatic conditions. Constant, scale-invariant parameters were assumed, which were found to be climate dependent. The main difference 10 compared with other cascade-based approaches is the assumption of dependency between the cascade generator and two properties of the time series values, rainfall volume and position in the rainfall sequence. Despite being built solely upon scaling properties, the model has been shown capable of reproducing not only the scaling behaviour of the observed data, but also the intermittent nature and the distributional properties of both individual volumes and event-related measures.

The rationale behind the disaggregation approach is to split each time interval (box) at a given resolution (for example 1 day) into two half of the original length (1/2 day). The procedure is continued as a cascade until the desired time resolution, i.e. first to $1 / 4$ day, then to $1 / 8$ of a day and so on. Each step is called a cascade step, with cascade level 0 as the longest time period with only one box (in the example a day). The rain volume of a box at an upper level can be distributed between the two lower boxes (probability $P x / x$ or all the rain can go into either of the boxes (probability $P 1 / 0$ or $P 0 / 1)$ ). The distribution of the volume between the two shorter intervals (boxes) is determined by multiplication with the cascade weights $(W)$, the distribution of which

is often termed the cascade generator, which fulfils the prescribed properties. The process is repeated for a number of levels, defined by the cascade step cs, until the rainfall is disaggregated into the desired resolution. The principle is demonstrated in Fig. 1.

\section{HESSD}

10, 4709-4738, 2013

IDF-curves for tropical india by random cascade modeling

A. Rana et al.

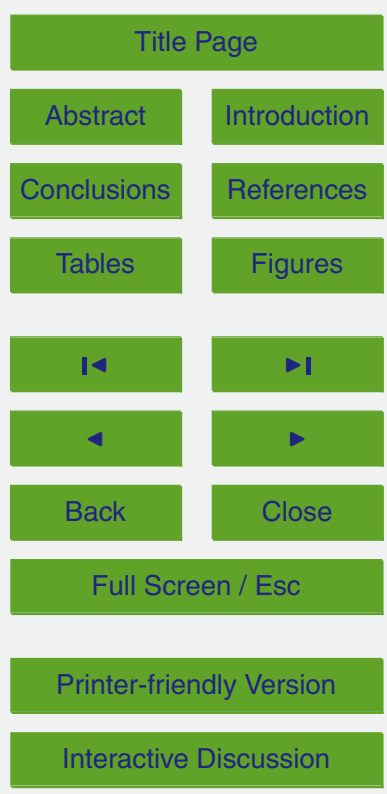


Through a random process it is first determined whether the rain volume should be distributed into two lower boxes or only into one of the probabilities $(P(\mathrm{x} / \mathrm{x})$ or $P(1 / 0)$ or $P(0 / 1))$. If $P(\mathrm{x} / \mathrm{x})$ was drawn in the random process, meaning that the rain volume should be distributed between two lower boxes, the distribution between the two boxes $5 \quad W_{1}$ and $W_{2}=1-W_{1}$ must be determined. In the original approach of Olsson (1998) and Güntner et al. (2001), the probabilities $P$ and the probability distribution $W x / x$ are assumed to be related to (1) position in the rainfall sequence and (2) rainfall volume. Concerning the former, it is reasonable to assume that the parameters are different for long, continuous rainfall events of stratiform character as compared to short-duration, 10 convective-type rainfalls. The wet boxes, i.e. time intervals with a rainfall volume $V>0$, can be characterised from their position in the rainfall series. The position classes used in the present study are same as suggested by Olsson (1998) and are divided into four categories. A starting box is a wet box preceded by a dry box $(V=0)$ and succeeded by a wet box, an enclosed box is preceded and succeeded by wet boxes, an ending box is 15 preceded by a wet box and succeeded by a dry box, and an isolated box is preceded and succeeded by dry boxes.

Concerning volume dependence, if the volume is large it is more likely that both halves of the interval contributes with non-zero volumes than if the volume is small. Olsson (1998) used two volume classes, below and above the median volume at the cascade step, with separate parameters. Since the focus of present study is the high and extreme intensities used for deriving IDF curves, a more detailed treatment of the probabilities' intensity dependence was found necessary. Firstly, a division into three volume classes ( $v c=1,2,3$ ) was used, separated by percentiles 33 and 67 of the values at the cascade step. Secondly, the variation of $P(\mathrm{X} / \mathrm{X})$ with volume was parameterised 25 as

$P(\mathrm{X} / \mathrm{X})=\alpha+\beta_{\mathrm{m}} * \mathrm{vc}$

where $\alpha$ is the intercept at $\mathrm{vc}=0, \beta_{\mathrm{m}}$ is the mean slope of linear regression obtained from all cascade steps and vc is volume class (1-3). This is expected to give a sharper

\section{HESSD}

$10,4709-4738,2013$

IDF-curves for tropical india by random cascade modeling

A. Rana et al.

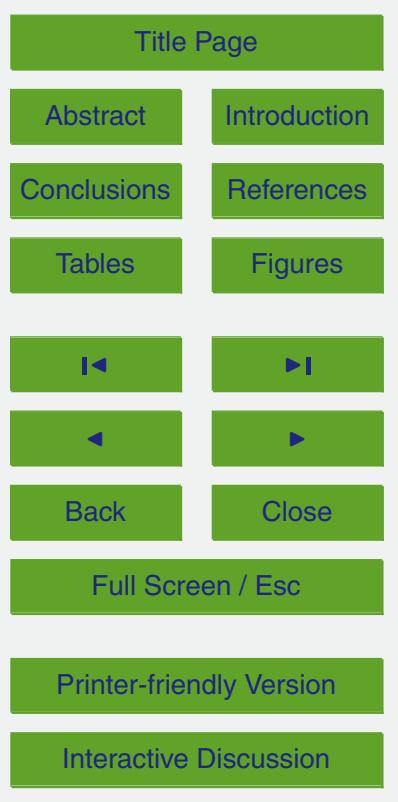


description of the volume impact than the previous, simpler approach. Since, as found by Güntner et al. (2001), $P(0 / 1)$ and $P(1 / 0)$ are generally approximately equal they can be estimated as $P(0 / 1)=P(1 / 0)=(1-P(\mathrm{x} / \mathrm{x})) / 2$.

The main development of the methodology performed in this paper is to allow for the 5 model parameters to vary also with time scale, as represented by the cascade step cs. Based on previous experience, this has emerged as a requirement for making the approach applicable at sub-hourly time steps. Therefore, in the present study $P(\mathrm{x} / \mathrm{x})$ is related to time scale by letting one of the parameters (called $\alpha$ ) to be dependent on cascade step. This is assumed to increase the possibility to describe the cascade 10 redistribution of rainfall also at very short time steps, associated with the internal temporal distribution of rainfall events. A mean value is used for $\beta, \beta_{\mathrm{m}}$ and $\alpha$ and is varied with cascade step as:

$\alpha=c 1+c 2 * c s$

where $c 1$ and $c 2$ are coefficients estimated from the aggregation process.

In Olsson (1998) the distribution of weights was determined from a uniform distribution so that $W=0.1$ has the same probability as $W=0.5$, at all cascade steps. Olsson (1998) found this valid when the lower box width exceeded at least $1 / 2 \mathrm{~h}$, i.e going from one hour to half hour time. However, when going to boxes with shorter time width, the distribution was centred towards $W=0.5$, the peak being most pronounced for the enclosed boxes. For box width exceeding a day, there was a tendency to an U-shaped distribution with probabilities of $W(\mathrm{x} / \mathrm{x})$ close to 0 and to 1 were higher than for $W=0.5$. Tests for the Swedish data, as well as data from other regions, have suggested that a symmetrical beta distribution provides a better fit to the observed distribution, as also used by e.g. Menabde and Sivapalan (2000). The symmetrical beta distribution is defined as:

$f(x)=\Gamma(2 a) / \Gamma^{2}(a)^{a-1}(1-x)^{a-1}$

where $\Gamma$ is the gamma function and $a$ is a parameter. The larger the parameter is, the more peaked is the distribution around $x=0.5$. For $a=1$, the distribution is uniform.

\section{HESSD}

10, 4709-4738, 2013

IDF-curves for tropical india by random cascade modeling

A. Rana et al.

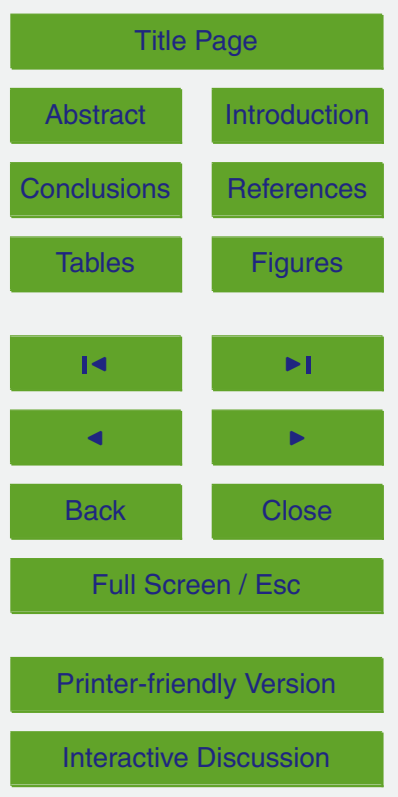

Interactive Discussion 
Based on own evaluation and previous experience in the literature, a reasonable scaledependent parameterisation is a log-log linear function of cascade step cs:

$\log (a)=c 3+c 4 * \log (c s)$

The disaggregation model parameters must be determined from an aggregation pro5 cess, in the Mumbai case by using short-term 2006 rainfall data. Starting from the high resolution, say $10 \mathrm{~min}$, of the available data, consecutive volumes from higher cascade levels (shorter time periods) are added two by two to get the volume at a lower level, say $20 \mathrm{~min}$. In this aggregation procedure the weights $W_{1}$ and $W_{2}$ can be directly estimated as the ratio of each to the sum of the two volumes. By repeating this procedure to successively lower resolutions all weights can be extracted, the probabilities $P$, the distribution $W \mathrm{x} / \mathrm{x}$, and their degree of scale-invariance assessed. The aggregation procedure was performed from the original 10-min resolution in seven cascade steps up to a time scale of $2^{7} \times 10 \mathrm{~min}=1280 \mathrm{~min}(21 \mathrm{~h} 20 \mathrm{~min})$, which is the attainable time scale closest to 1 day.

After the cascade model parameters have been determined, the procedure of disaggregating daily data to gradually higher time resolution is straight-forward. First, through a random process it is determined whether the total rain volume in the interval should be distributed into both halves or only into one half (determined by probabilities $P(\mathrm{x} / \mathrm{x})$, $P(1 / 0)$ and $P(0 / 1))$. Then if $P(\mathrm{x} / \mathrm{x})$ was drawn in the random process, meaning that the 20 rain volume should be distributed between the two halves, the weights $W_{1}$ and $W_{2}=$ $1-W_{1}$ are estimated by random sampling from a beta distribution with parameter according to Eq. (4).

Parameter estimation and settings defined to fit the observed data using scale invariant properties of observed rainfall time series were derived. The evaluation of the applicable scale range of the cascade model designed to represent the temporal structure of rainfall was performed as a first step. The probability values were estimated and weights were extracted. To do so, the observed 10-min time series were aggregated into daily values $(1280 \mathrm{~min})$ in the estimation step and then again disaggregated to

\section{HESSD}

10, 4709-4738, 2013

IDF-curves for tropical india by random cascade modeling

A. Rana et al.

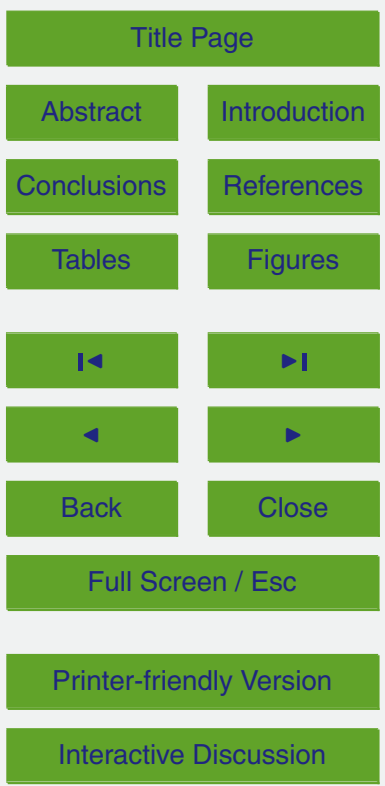


10 min values using 7 cascade steps and calibrated in the same series (Objective 1 of the study). This disaggregation was reproduced with 1000 realizations and means of empirical probabilities obtained after disaggregation were used as estimates of probability. The performance of model was investigated by disaggregating/redistributing the 5 aggregated 2006 data and computing the statistics with the data; accounting for objective 2 of the study. This was then followed by disaggregation of the historical dataset; for objective 3 of the study. The temporal rainfall disaggregation was also done in 1000 realizations and the maxima were then used for analysis and establishing IDF curves. The procedure was shown in Fig. 2.

\subsection{Establishment of IDF curves}

The principal characteristics of a storm are its intensity, duration, total volume, and frequency or recurrence interval also called return period. Intensity-duration-frequency (IDF) analysis is used to capture the essential characteristics of point rainfall for shorter durations. IDF analysis provides a convenient tool to summarize rainfall information, 5 and is used in municipal storm water management practice. In the IDF approach the rain intensity is the rain volume over a given time, the storm duration. The less the frequency of storm the stronger is the intensity.

IDF curves are developed by using long time series of rain observation to compute rain volume over fixed duration. In this study the disaggregated data produced in above procedure is used to compute IDF relations. The IDF analysis starts by gathering time series records of different durations by computing mean over fixed running time durations. Annual maxima were extracted from the records for all durations. The durations that were taken in consideration were $10,20,40,80,160$, and $320 \mathrm{~min}$. The annual extreme data was then fit to a probability distribution in order to estimate rainfall quan-

tities of very low frequencies. The fit of probability distribution was performed in order to standardize the character of rainfall. Gumbel's extreme value distribution was used for fitting the extremes. For not so extreme events, the return periods can simply be

\section{HESSD}

10, 4709-4738, 2013

IDF-curves for tropical india by random cascade modeling

A. Rana et al.

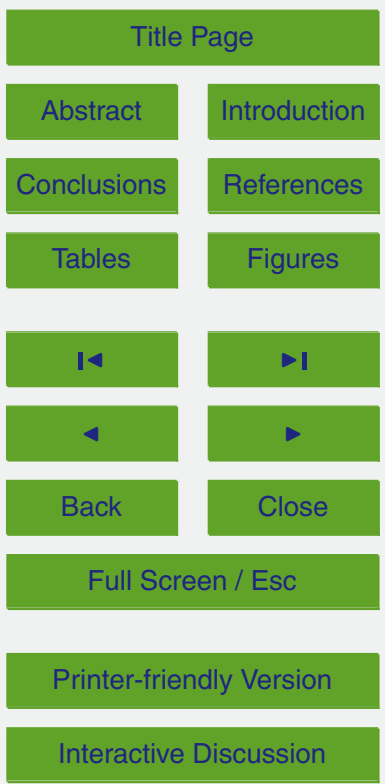


estimated from the number of events in $\sim 50 \mathrm{yr}$ data considered, for example the 5th largest value would correspond to $10 \mathrm{yr}$ return period.

\section{Results and discussion}

\subsection{Evaluation of random cascade model}

5 The relationship between $P$ and volume class at each cascade step was derived for the 2006 data. The probabilities $P(\mathrm{x} / \mathrm{x})$ for all the four different type of boxes are shown in Table 2. The probabilities increase with the volume class; the wetter it is, the more likely that the rain is distributed into both halves of the interval. In order to use the equation $\alpha+\beta_{\mathrm{m}} *$ vc a mean slope, $\beta_{\mathrm{m}}$, was determined for each type of box. Thus, the slope $\beta$ 10 remains relatively constant for the different steps. However, the observed variation was modified to a fixed slope so that the intercept varied with cascade step. The $\alpha$-values are not very dependent on the cascade step, but varied $\alpha$-values gave somewhat better results. The assumed linear dependence on cascade steps is sometimes weak but based on earlier application of the model in different studies the linear assumption is 15 kept. Moreover large variations in the data (attributed to short data period and associated variability) make it difficult to use any alternate model than the linear one. Overall the linear variation is in terms with the variation followed by the observed data. The probability $P(1 / 0)$ was found to be higher than $P(0 / 1)$ for ending boxes, but lower for starting boxes. For isolated and enclosed boxes the probabilities were the same. Since the number of enclosed boxes dominate, it is reasonable to assume the probabilities $P(1 / 0)$ and $P(0 / 1)$ to be same and equal to $(1-P(\mathrm{x} / \mathrm{x})) / 2$ as suggested above.

Figure 3 shows fitted beta distributions (lines) to the empirical histograms (bars). The overall fit is reasonable at high cascade steps, i.e. large time scales, but when the number of values is small, and the histograms as well, the fits becomes uncertain. The distribution parameter is close to 1 for cascade step 3 and larger ( $3 \mathrm{~h}$ or shorter time scale). This is different from what was found in the Swedish study. This in contrast says

\section{HESSD}

10, 4709-4738, 2013

IDF-curves for tropical india by random cascade modeling

A. Rana et al.

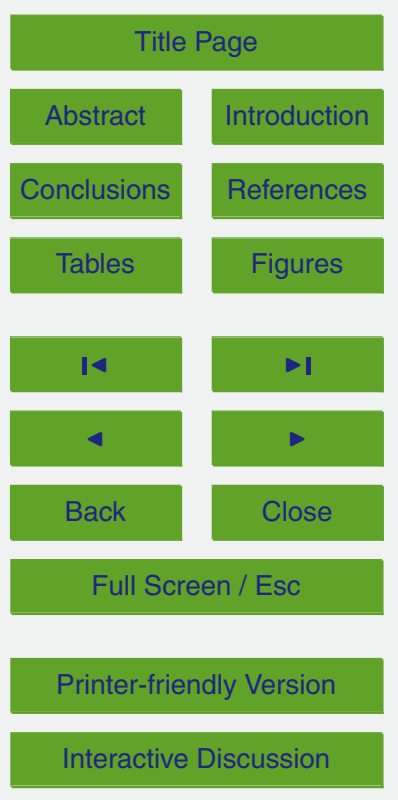


that the rain intensity may vary during a storm even for the time scales $10-20 \mathrm{~min}$. As seen from the Fig. 3 some improvement is achieved when using the beta distribution as compared to a uniform distribution for the lower cascade steps. For the enclosed boxes, which dominate, and the isolated boxes the fit is good. Figure 4 shows how the 5 beta distribution parameter a varies with cascade step. For starting and ending boxes, $a$ is relatively constant and the joint mean appears to be a satisfactory approximation of the observed. This can be observed at each cascade step.

The results can to some extent be compared with earlier applications of the approach. In his Swedish study Olsson (1998) found the disaggregation technique to ap10 plicable for durations exceeding one hour. Since scale invariance did not apply for lower durations, he only briefly mentioned about his results for short durations and did not perform a serious analysis for the shorter durations. Güntner et al. (2001) concentrated on the one-hour rain volumes derived from disaggregation of daily data. Averaged over all cascade steps $P(\mathrm{x} / \mathrm{x})$ was as high as 0.95 for enclosed boxes of high volume class 15 for stations in Wales and Scotland with large annual precipitation (2500 and $1400 \mathrm{~mm}$ ). For stations in Brazil with annual precipitation varying between 550 and $950 \mathrm{~mm}, P(\mathrm{x} / \mathrm{x})$ was about 0.7, and for a station in England with $600 \mathrm{~mm}$ annual precipitation it was 0.8 . The w-distribution (step from 2 to $1 \mathrm{~h}$ ) was peaked for the British stations indicating that the rain intensity is fairly uniform over an hour. When trying to fit to a beta-distribution the parameter a is about 3-3.5 for the wet volume class; there was only two volume classes in this study. For the tropical Brazilian climate the w-distribution is rather uniform. It is even so that for the wet volume class, the highest probabilities are for w close 0 and close to 1 , which indicates intensity variations within the hour. This agrees with the Mumbai data, only that the same seems to be valid also for shorter time scales in 25 Mumbai.

\subsection{Performance of disaggregation model}

The observed (data that was used for parameter estimation in cascade model i.e. JulyDecember 2006) and the generated rainfall time series at different cascade steps in the 4720

\section{HESSD}

10, 4709-4738, 2013

IDF-curves for tropical india by random cascade modeling

A. Rana et al.

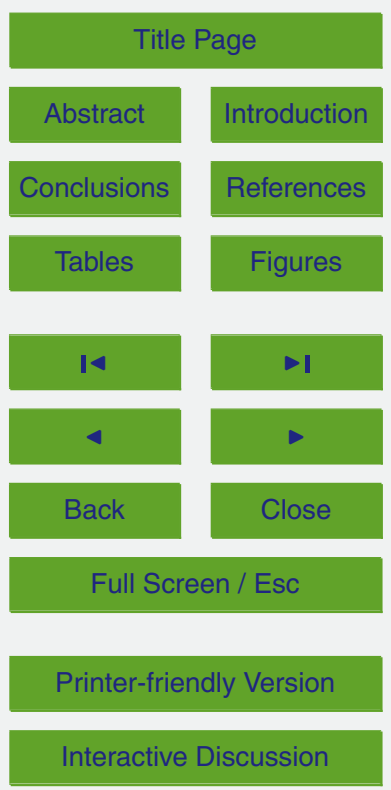


model are compared in Table 3. The agreement is very good for the three lower cascade steps (larger durations $~ 24-6 \mathrm{~h}$ ) than at higher ones as noticed in terms of zero values, number of events more than $25 \mathrm{~mm}$ and maximum rainfall, mean and standard deviation (Table 3). At higher cascade steps the number of zero events and the mean 5 is well determined but not the high values. The computed maximum is too low (about $20 \%$ ) for durations 80 and $160 \mathrm{~min}$, and much too high (around $40 \%$ ) for durations 10 and $20 \mathrm{~min}$. The aggregative property of the model is well preserved as the total rainfall in all the observed and generated series is equal to $2170 \mathrm{~mm}$. The fraction of no rainfall periods and the number of large events are very well described when the duration is $6 \mathrm{~h}$ or more. Number of events more than $25 \mathrm{~mm}$ and percentage of zero rainfall are overestimated for 20 and 10 min data. Mean and S.D. are well preserved in all the cascade steps. Maximum values were preserved in lower cascade steps and deteriorate at cascade step 5 and above. Difference of up to $10 \mathrm{~mm}$ is noticed in cascade step 7 when we have $10 \mathrm{~min}$ data. Overall the extreme values for $1 \mathrm{~h}$ durations and above 15 are well preserved and are well related to observations presented by Deshpande et al. (2012), where the authors have studied observations from same station upto $1 \mathrm{~h}$ of temporal resolution.

The performance of the model is also shown in Fig. 5. The probability of zero rainfall, Po, was computed from generated data for the model at all scales $c s=0, \ldots, 7$ and compared with observed data according to Fig. 5a. The model performance was satisfactory for preservation of intermittency, with no differences at cs $=0$ (1280 $\mathrm{min}$ ), as by definition the model is conserving mass across the scales. The model performance was good in preserving the rainfall properties with relative percentage error ranging from -2 to $-5 \%$ at each higher cascade step in terms of zero values. Daily rainfall maxima $\mathrm{Ht}$ and standard deviation of maxima $\mathrm{s}(\mathrm{Ht})$ for the whole data period were determined from generated 10-min data for all 1000 realizations. This was done for every realization of generated data and compared with those derived from observed values for each cascade step and are presented in Fig. $5 \mathrm{~b}$ and c. The model generally performed well with both means and standard deviation of maxima at each cascade steps

\section{HESSD}

10, 4709-4738, 2013

IDF-curves for tropical india by random cascade modeling

A. Rana et al.

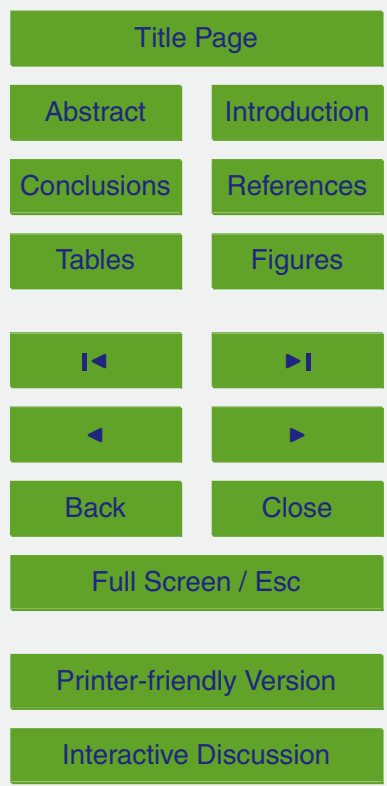


and same can be inferred from the box plots in Fig. 5b and c. The model has underestimated the mean of maxima in 1000 realizations as compared to observed values for first 4 cascade steps, equal in 5th cascade step and overestimated it in 6th and 7th cascade steps. Similarly S.D. is underestimated for first 4 cascade steps and equal in 5 last three cascade steps inferring less variability in the generated data for 10, 20 and $40 \mathrm{~min}$.

The model has thus overestimated the variability with longer durations i.e. lower cascade steps and equal in the higher cascade steps. Maximum daily values of generated daily rainfall are compared with that of observed in Fig. 6. It is seen that the model 10 has performed well in preserving extremes upto 5 cascade steps as was shown in Table 3. The model seems to overestimate daily maximum values at 6 th and 7 th cascade steps. Güntner et al. (2001) report overestimation of the extreme one hour rain intensities, more so for the British stations than for the Brazilian stations. The disaggregation of the Mumbai-data shows clear overestimation of the number of events and of the extremes only when durations 10 and $20 \mathrm{~min}$ are considered. The intense storms are simulated well for time scale $40 \mathrm{~min}$.

\subsection{Establishment of IDF curves}

After the parameters were determined and the disaggregation was performed on the 1951-2004 daily rain data, the new computed rain series were used to determine IDF curves as already discussed. The derived relations for Mumbai are shown in Fig. 7. From the graph it is seen that intensity and frequency of extreme events in Mumbai are quite high compared to the current design standards in the city. The intensity of $10 \mathrm{~min}$ duration rainfall is 125,137 and $150 \mathrm{~mm} \mathrm{~h}^{-1}$ for return periods of 20,30 and $40 \mathrm{yr}$, respectively. $30 \mathrm{yr}$ are considered the life expectancy of urban infrastructure and (CPHEEO), Ministry of Urban Development, Government of India. For the same return period of 20,30 and $40 \mathrm{yr}, 30 \mathrm{~min}$ duration rainfall is 87,95 and $102 \mathrm{~mm} \mathrm{~h}^{-1}$, respectively, and $60 \mathrm{~min}$ duration is 60,65 and $70 \mathrm{~mm} \mathrm{~h}^{-1}$, respectively. This is high

HESSD

10, 4709-4738, 2013

IDF-curves for tropical india by random cascade modeling

A. Rana et al.

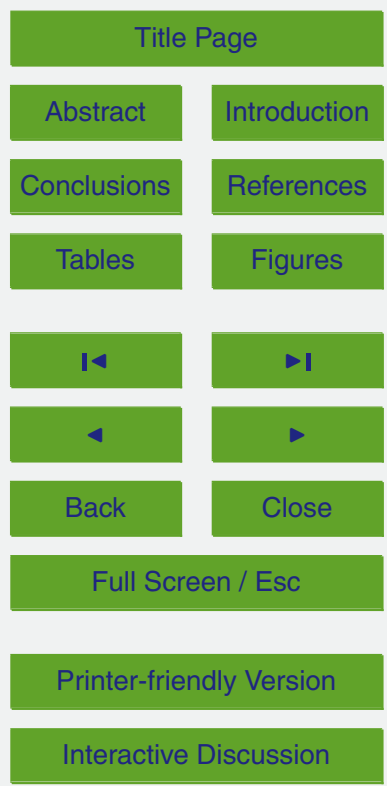


compared to current design standard for Mumbai city which is only $25 \mathrm{~mm} \mathrm{~h}^{-1}$ at low tide (City development plan 2005-2025, Municipal Corporation of Mumbai). According to Intensity-Frequency relation of Fig. 7 it corresponds to return period of less than a year. The established extreme values from the IDF curves are comparable to those 5 of a study performed by Deshpande et al. (2012) where the authors have outlined the extreme events for $1,3,6$ and $12 \mathrm{~h}$ for Mumbai station. It can also be noted that $1 \mathrm{hr}$ extreme rainfall for Mumbai in the study is $113 \mathrm{~mm}$ for the data period 1969-2004 which is comparable to the established IDF relations. It can also be said that the IDF relations hold true even when they are not adjusted to the overestimation of extreme values for cascade step 5 and above. This can be attributed to small dataset for comparison of the performance of cascade model.

Rainfall events are often used as the basis for determining the design capacity of the storm-water structures, but due to probabilistic nature of rainfall there is always a risk of exceedance of design capacity. There is always a hydrological risk associated with any design. The above technique for developing IDF curve from long daily precipitation series can be used for better design of storm water system and for risk analysis of cities not only in Mumbai but also for other cities with the same type of rains, where shortterm data is lacking. It should be noted that most of the natural drains in Mumbai city are absent due to population pressure, developmental activities and/or encroachments in those areas. Man-made drains, need to be repaired or rebuilt. The present IDF curves can be used for planning drainage system in the city along with estimation of storm runoff, storm frequency, intensity of rainfall etc. Planners can decide upon drainage system based on level of performance or acceptable level of risk of the infrastructure system. It can be understood that the performance level of a given urban drainage corresponding risk of system failure. Such factors are, for example, the addition of impervious surfaces, the extension of the network, structural aging of the network and the maintenance quality along with change in intensity and frequency of inflow into the

HESSD

$10,4709-4738,2013$

IDF-curves for tropical india by random cascade modeling

A. Rana et al.

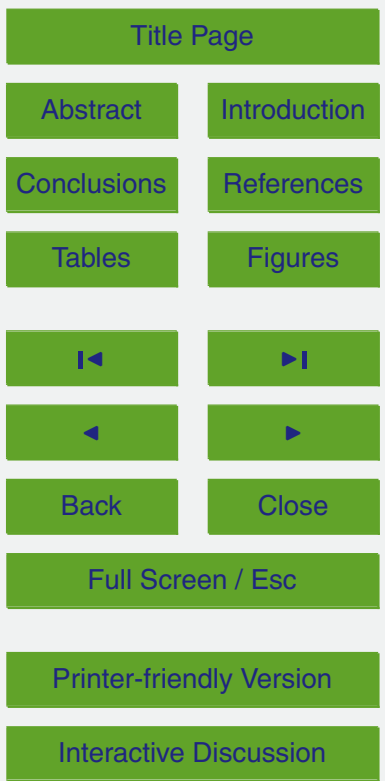


system. The response of the system to intense rainfall events is, to some extent, used as an indicator of the level of service provided, which has to be looked into for Mumbai.

\section{Conclusions}

In most cities there is a need of information about short-term rains for design of in5 frastructure. In the present study it was found that rainfall disaggregation can be used to derive short term rain information for tropical rains with about $30 \mathrm{~min}$ resolutions, when only daily data is available. It can help in providing fine time scale precipitation data necessary for many engineering and environmental applications. In the present study multiplicative cascade based model for disaggregation of rainfall was used. Strict scaling, i.e. parameters independent of time scale, was not used. For shorter times better agreement between model results and observations was found, when the parameters where allowed to vary with scale according to simple linear functions. The cascade weights' volume dependence was found to be significant; therefore three volume classes were introduced instead of the previously used two classes. Although, the 15 parameters were related to time scale, the maximum values were overestimated for time scales less than about 30 min.

It should be emphasized that this is intended as a real-world demonstration case with limited possibilities for proper validation and uncertainty assessment. Even though the fitted model seemed to overall reasonably well reproduce key statistics over the whole range of time scales considered, distinct deviations were found and further no crossvalidation was attainable. Clearly the deviations can partly be attributed to imprecise parameter estimates from the limited amount of short-term data available, but also the model structure and scale-dependent relationships are likely not strictly followed by the rainfall data. More in-depth analyses of the impact of high-resolution data availability

The IDF curves derived for Mumbai indicates that the present design standard values are very low. The design is for a storm with less than annual return period. Thus,

HESSD

10, 4709-4738, 2013

IDF-curves for tropical india by random cascade modeling

A. Rana et al.

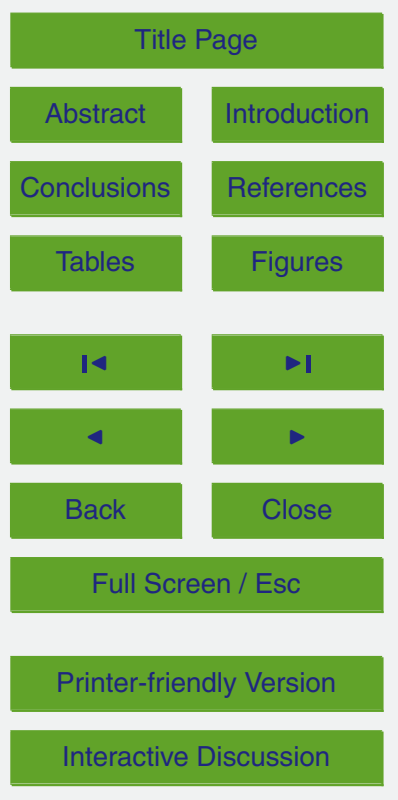


flooding is expected to occur several times in a year, which in fact also happens. In urban areas, it is very important to study the effects of urban conditions on rainfallrunoff relationships. Changes in the physical characteristics of urban areas change the runoff response of the area along with natural forces. Thus, it is necessary to evaluate 5 the effects of changes in precipitation and human interference on the natural drainage patterns of the urban area. Infrastructural planning of urban area should require careful attention to urban drainage characteristics. This high intensity/frequency of precipitation is alarming and main problem for Mumbai.

Acknowledgements. he authors acknowledges support from the Swedish Research Council 10

Formas and the Swedish International Development Cooperation Agency (SIDA).

\section{References}

Bo, Z. Q., Islam, S., and Eltahir, E. A. B.: Aggregation-Disaggregation Properties of a Stochastic Rainfall Model, Water Resour. Res., 30, 3423-3435, 1994.

Connolly, R. D., Schirmer, J., and Dunn, P. K.: A daily rainfall disaggregation model, Agr. Forest 15 Meteorol., 92, 105-117, 1998.

Cowpertwait, P. S. P., O'Connell, P. E., Metcalfe, A. V., and Mawdsley, J. A.: Stochastic point process modelling of rainfall. II. Regionalisation and disaggregation, J. Hydrol., 175, 47-65, 1996.

Deshpande, N. R., Kulkarni, A., and Krishna Kumar, K.: Characteristic features of hourly rainfall in India, Int. J. Climatol., 32, 1730-1744, doi:10.1002/joc.2375, 2012.

Econopouly, T. W., Davis, D. R., and Woolhiser, D. A.: Parameter transferability for a daily rainfall disaggregation model, J. Hydrol., 118, 209-228, 1990.

Gaume, E., Mouhous, N., and Andrieu, H.: Rainfall stochastic disaggregation models: Calibration and validation of a multiplicative cascade model, Adv. Water Resour., 30, 1301-1319, 252007.

Glasbey, C. A., Cooper, G., and McGechan, M. B.: Disaggregation of daily rainfall by conditional simulation from a point-process model, J. Hydrol., 165, 1-9, 1995.

\section{HESSD}

10, 4709-4738, 2013

IDF-curves for tropical india by random cascade modeling

A. Rana et al.

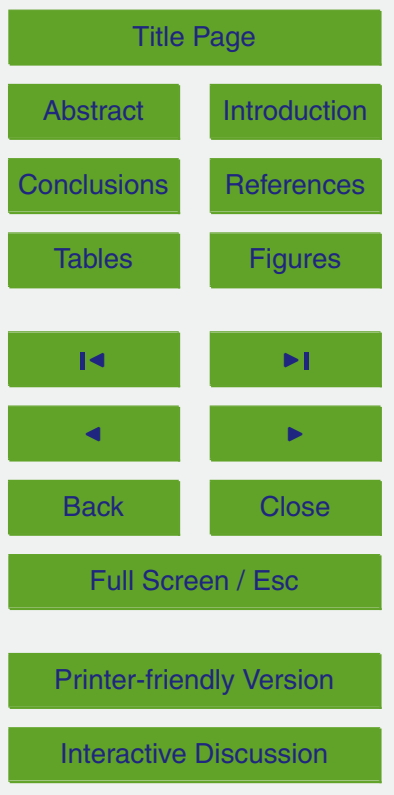


Güntner, A., Olsson, J., Calver, A., and Gannon, B.: Cascade-based disaggregation of continuous rainfall time series: the influence of climate, Hydrol. Earth Syst. Sci., 5, 145-164, doi:10.5194/hess-5-145-2001, 2001.

Harris, D., Menabde, M., Seed, A., and Austin, G.: Multifractal characterization of rain fields with a strong orographic influence, J. Geophys. Res.-Atmos., 101, 26405-26414, 1996.

Hershenhorn, J. and Woolhiser, D. A.: Disaggregation of daily rainfall, J. Hydrol., 95, 299-322, 1987.

Hubert, P., Tessier, Y., Lovejoy, S., Schertzer, D., Schmitt, F., Ladoy, P., Carbonnel, J. P., Violette, S., and Desurosne, I.: Multifractals and Extreme Rainfall Events, Geophys. Res. Lett., 20, $10 \quad$ 931-934, 1993.

Jebari, S., Berndtsson, R., Olsson, J., and Bahri, A.: Soil erosion estimation based on rainfall disaggregation, J. Hydrol., 436-437, 102-110, 2012.

Kumke, T.: Book Review: Regional Frequency Analysis: An Approach Based on L-Moments By J. R. M. Hosking and J. R. Wallis, Cambridge University Press, Cambridge, UK, 1997, 224 p., \$69.95 (U.S.), ISBN 0-521-43045-3 hardback, Math. Geol., 33, 535-537, doi:10.1023/a:1011045130979, 2001.

Langousis, A. and Veneziano, D.: Intensity-duration-frequency curves from scaling representations of rainfall, Water Resour Res, 43, W02422, doi:10.1029/2006wr005245, 2007.

Licznar, P., Łomotowski, J., and Rupp, D. E.: Random cascade driven rainfall disaggregation for urban hydrology: An evaluation of six models and a new generator, Atmos. Res., 99, 563-578, 2011.

Menabde, M. and Sivapalan, M.: Modeling of rainfall time series and extremes using bounded random cascades and levy-stable distributions, Water Resour. Res., 36, 3293-3300, doi:10.1029/2000wr900197, 2000.

Molnar, P. and Burlando, P.: Preservation of rainfall properties in stochastic disaggregation by a simple random cascade model, Atmos. Res., 77, 137-151, 2005.

Mumbai Municipal Corporation: "City development Plan 2005-2025, Chapter 2.6, Storm Water Drainage", available at: http://www.mcgm.gov.in/irj/portal/anonymous?NavigationTarget= navurl://095e1c7b9486b1423b881dce8b106978 (last access: 10 January 2013), 2005.

30 Olsson, J.: Limits and characteristics of the multifractal behaviour of a high-resolution rainfall time series, Nonlin. Processes Geophys., 2, 23-29, doi:10.5194/npg-2-23-1995, 1995.

Olsson, J.: Evaluation of a scaling cascade model for temporal rain- fall disaggregation, Hydrol. Earth Syst. Sci., 2, 19-30, doi:10.5194/hess-2-19-1998, 1998.
HESSD

10, 4709-4738, 2013

IDF-curves for

tropical india by

random cascade

modeling

A. Rana et al.

Title Page

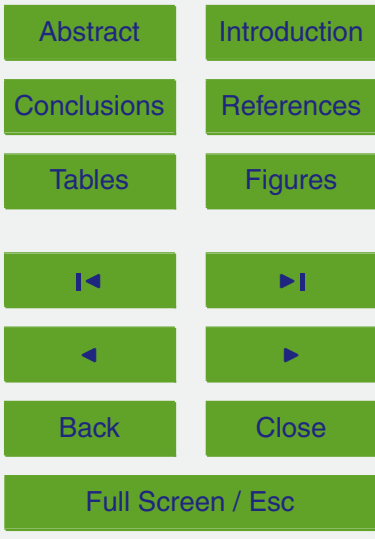

Printer-friendly Version

Interactive Discussion 
Over, T. M. and Gupta, V. K.: Statistical Analysis of Mesoscale Rainfall: Dependence of a Random Cascade Generator on Large-Scale Forcing, J. Appl. Meteorol., 33, 1526-1542, doi:10.1175/1520-0450(1994)033<1526:saomrd>2.0.co;2, 1994.

Rana, A., Uvo, C., Bengtsson, L., and Parth Sarthi, P.: Trend analysis for rainfall in Delhi and Mumbai, India, Clim. Dynam., 38, 45-56, doi:10.1007/s00382-011-1083-4, 2012.

Rupp, D. E., Keim, R. F., Ossiander, M., Brugnach, M., and Selker, J. S.: Time scale and intensity dependency in multiplicative cascades for temporal rainfall disaggregation, Water Resour. Res., 45, W07409, doi:10.1029/2008wr007321, 2009.

Schertzer, D. and Lovejoy, S.: Physical Modeling and Analysis of Rain and Clouds by Anisotropic Scaling Multiplicative Processes, J. Geophys. Res.-Atmos., 92, 9693-9714, 1987.

Svensson, C., Olsson, J., and Berndtsson, R.: Multifractal properties of daily rainfall in two different climates, Water Resour. Res., 32, 2463-2472, 1996.

Tessier, Y., Lovejoy, S., and Schertzer, D.: Universal multrifractals: Theory and observations for rain and clouds, J. Appl. Meteorol. 32, 223-250, 1993.

IDF-curves for tropical india by

random cascade

modeling

A. Rana et al.

Title Page

Abstract Introduction

Conclusions References

Tables Figures

14 $\rightarrow$

4

Back

Close

Full Screen / Esc

Printer-friendly Version

Interactive Discussion 


\section{HESSD}

10, 4709-4738, 2013

IDF-curves for tropical india by random cascade modeling

Table 1a. Statistics of daily data for historical period (1951-2004), July-December 1951-2004 and July-December 2006.

\begin{tabular}{lrrrrr}
\hline & $\begin{array}{r}\text { Daily } \\
\text { Mean } \\
(\mathrm{mm})\end{array}$ & $\begin{array}{r}\text { Daily } \\
\text { S.D. } \\
\left(\mathrm{mm} \mathrm{day}^{-1}\right)\end{array}$ & $\begin{array}{r}\text { Mean } \\
\text { Volume } \\
(\mathrm{mm})\end{array}$ & $\begin{array}{r}\text { Mean } \\
\text { Annual } \\
\text { daily }\end{array}$ \\
$\begin{array}{l}\text { Max }(\mathrm{mm}) \\
\text { Data Period }\end{array}$ & 5.93 & 18.61 & 2165 & 162 & $\begin{array}{r}\text { Maximum } \\
\left(\mathrm{mm} \mathrm{day}^{-1}\right)\end{array}$ \\
\hline Ju51-2004 & 8.97 & 21.76 & 1643 & 162 & 293.4 \\
July-December 1951-2004-December 2006 & 13.64 & 34.06 & 2170 & 266 & 266 \\
\hline
\end{tabular}

A. Rana et al.

Title Page

Abstract Introduction

Conclusions

References

Tables

Figures

14

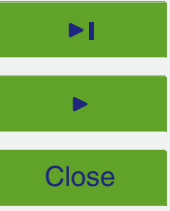

Back

Full Screen / Esc

Printer-friendly Version

Interactive Discussion 
Table 1b. Statistics of short-term precipitation during July-December 2006.

\begin{tabular}{lrrrrrrr}
\hline $\begin{array}{l}\text { Volume }(\mathrm{mm}) / \\
\text { Duration }\end{array}$ & $24 \mathrm{~h}$ & $12 \mathrm{~h}$ & $6 \mathrm{~h}$ & $3 \mathrm{~h}$ & $1 \mathrm{~h}$ & $30 \mathrm{~min}$ & $10 \mathrm{~min}$ \\
\hline Largest & 266 & 189 & 125.73 & 102.88 & 41.66 & 24.13 & 18.29 \\
2nd Largest & 196.05 & 124.71 & 100.84 & 65.53 & 40.39 & 22.61 & 16.76 \\
3rd Largest & 144 & 118.87 & 69.33 & 61.49 & 29.46 & 22.61 & 16.26 \\
4th Largest & 140.21 & 77.18 & 69.07 & 59.42 & 28.44 & 21.08 & 14.22 \\
5th Largest & 117.03 & 76.91 & 67.53 & 58.16 & 28.2 & 20.83 & 13.21 \\
\hline
\end{tabular}

HESSD

10, 4709-4738, 2013

IDF-curves for tropical india by random cascade modeling

\section{A. Rana et al.}

\section{Title Page}

Abstract Introduction

Conclusions

References

Tables Figures

14

4

Back

Close

Full Screen / Esc

Printer-friendly Version

Interactive Discussion 
Table 2. Probabilities $P(\mathrm{x} / \mathrm{x})$ as function of volume class, cascade step and type of box.

HESSD

Isolated $\operatorname{Box}(\beta$ model $=0.15)$

\begin{tabular}{|c|c|c|c|c|c|c|c|c|}
\hline $\begin{array}{l}\text { Volume Class/ } \\
\text { Cascade Step }\end{array}$ & 1 & 2 & 3 & 4 & 5 & 6 & 7 & Mean \\
\hline 1 & 0.00 & 0.00 & 0.19 & 0.06 & 0.04 & 0.00 & 0.00 & 0.04 \\
\hline 2 & 0.16 & 0.25 & 0.24 & 0.12 & 0.25 & 0.10 & 0.08 & 0.17 \\
\hline 3 & 0.43 & 0.36 & 0.31 & 0.38 & 0.40 & 0.36 & 0.22 & 0.35 \\
\hline$\alpha_{\text {cascade }}$ & -0.12 & -0.11 & -0.07 & -0.13 & -0.08 & -0.16 & -0.21 & -0.12 \\
\hline$\alpha_{\text {model }}$ & -0.08 & -0.10 & -0.11 & -0.12 & -0.14 & -0.15 & -0.17 & -0.12 \\
\hline \multicolumn{9}{|c|}{ Starting $\operatorname{Box}(\beta$ model $=0.22)$} \\
\hline 1 & 0.19 & 0.07 & 0.08 & 0.09 & 0.09 & 0.21 & 0.21 & 0.13 \\
\hline 2 & 0.30 & 0.32 & 0.23 & 0.19 & 0.45 & 0.35 & 0.29 & 0.30 \\
\hline 3 & 0.42 & 0.53 & 0.44 & 0.55 & 0.53 & 0.58 & 0.62 & 0.52 \\
\hline$\alpha_{\text {cascade }}$ & -0.09 & -0.09 & -0.14 & -0.12 & -0.03 & -0.01 & -0.02 & -0.07 \\
\hline$\alpha_{\text {model }}$ & -0.14 & -0.13 & -0.11 & -0.10 & -0.09 & -0.08 & -0.06 & -0.10 \\
\hline \multicolumn{9}{|c|}{ Enclosed Box $(\beta$ model $=0.29)$} \\
\hline 1 & 0.45 & 0.35 & 0.28 & 0.25 & 0.26 & 0.47 & 0.59 & 0.38 \\
\hline 2 & 0.85 & 0.75 & 0.67 & 0.66 & 0.73 & 0.81 & 0.86 & 0.76 \\
\hline 3 & 0.97 & 0.93 & 0.91 & 0.94 & 0.91 & 0.89 & 0.95 & 0.93 \\
\hline$\alpha_{\text {cascade }}$ & 0.21 & 0.13 & 0.07 & 0.07 & 0.09 & 0.18 & 0.25 & 0.14 \\
\hline$\alpha_{\text {model }}$ & 0.12 & 0.13 & 0.13 & 0.14 & 0.15 & 0.16 & 0.17 & 0.14 \\
\hline \multicolumn{9}{|c|}{ Ending Box $(\beta$ model $=0.23)$} \\
\hline 1 & 0.15 & 0.00 & 0.07 & 0.09 & 0.05 & 0.03 & 0.07 & 0.07 \\
\hline 2 & 0.42 & 0.37 & 0.18 & 0.31 & 0.48 & 0.29 & 0.62 & 0.38 \\
\hline 3 & 0.52 & 0.56 & 0.47 & 0.44 & 0.60 & 0.41 & 0.64 & 0.52 \\
\hline$\alpha_{\text {cascade }}$ & -0.09 & -0.14 & -0.21 & -0.17 & -0.08 & -0.21 & -0.01 & -0.13 \\
\hline$\alpha_{\text {model }}$ & -0.14 & -0.13 & -0.11 & -0.10 & -0.09 & -0.08 & -0.06 & -0.10 \\
\hline
\end{tabular}

10, 4709-4738, 2013

IDF-curves for tropical india by random cascade modeling

A. Rana et al.

Title Page

Abstract Introduction

Conclusions

References

Tables

Figures

14

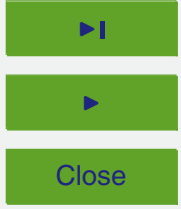

Full Screen / Esc

Printer-friendly Version

Interactive Discussion 
Table 3. Rainfall characteristics related to the observed and model generated series from data period July-December 2006 (generated series data is mean of all 100 realizations).

\begin{tabular}{|c|c|c|c|c|c|c|}
\hline Scale & $\begin{array}{l}\text { Time } \\
\text { Series }\end{array}$ & $\begin{array}{r}\text { Zero } \\
\text { Values (\%) }\end{array}$ & $\begin{array}{r}\text { No. of } \\
\text { Events } \\
>25 \mathrm{~mm}\end{array}$ & $\begin{array}{l}\text { Mean } \\
(\mathrm{mm})\end{array}$ & $\begin{array}{l}\text { S.D. } \\
(\mathrm{mm})\end{array}$ & $\begin{array}{r}\text { Maximum } \\
(\mathrm{mm})\end{array}$ \\
\hline \multirow{2}{*}{$1280 \mathrm{~min}$} & Observed & 44.65 & 18 & 13.65 & 34.06 & 265.60 \\
\hline & Modelled & 44.65 & 18 & 13.64 & 34.06 & 265.50 \\
\hline \multirow[b]{2}{*}{$640 \mathrm{~min}$} & Observed & 51.26 & 19 & 6.82 & 19.29 & 188.69 \\
\hline & Modelled & 51.43 & 22 & 6.82 & 18.62 & 173.64 \\
\hline \multirow{2}{*}{$320 \mathrm{~min}$} & Observed & 58.33 & 22 & 3.41 & 11.01 & 125.73 \\
\hline & Modelled & 57.96 & 21 & 3.41 & 10.36 & 117.04 \\
\hline \multirow[b]{2}{*}{$160 \mathrm{~min}$} & Observed & 68.16 & 19 & 1.71 & 6.40 & 102.88 \\
\hline & Modelled & 65.13 & 16 & 1.71 & 5.91 & 86.00 \\
\hline \multirow{2}{*}{$80 \mathrm{~min}$} & Observed & 77.12 & 11 & 0.85 & 3.77 & 82.05 \\
\hline & Modelled & 72.91 & 11 & 0.85 & 3.43 & 62.73 \\
\hline \multirow[b]{2}{*}{$40 \mathrm{~min}$} & Observed & 84.04 & 7 & 0.43 & 2.08 & 41.66 \\
\hline & Modelled & 80.15 & 7 & 0.43 & 2.03 & 48.37 \\
\hline \multirow[b]{2}{*}{$20 \mathrm{~min}$} & Observed & 88.85 & 0 & 0.21 & 1.17 & 24.13 \\
\hline & Modelled & 86.02 & 4 & 0.21 & 1.21 & 36.27 \\
\hline \multirow{2}{*}{$10 \mathrm{~min}$} & Observed & 92.13 & 0 & 0.11 & 0.65 & 18.29 \\
\hline & Modelled & 90.43 & 2 & 0.11 & 0.73 & 27.45 \\
\hline
\end{tabular}

\section{HESSD}

IDF-curves for tropical india by random cascade modeling

\section{A. Rana et al.}

Title Page

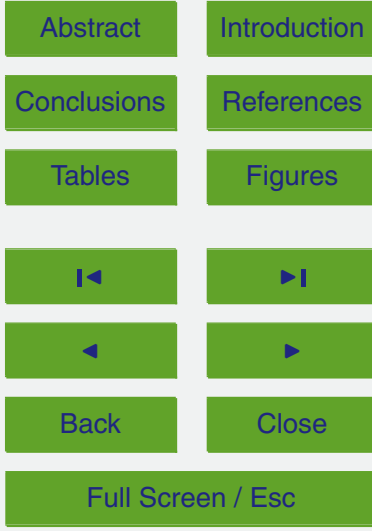

Printer-friendly Version

Interactive Discussion 
Cascade Step:

0

1

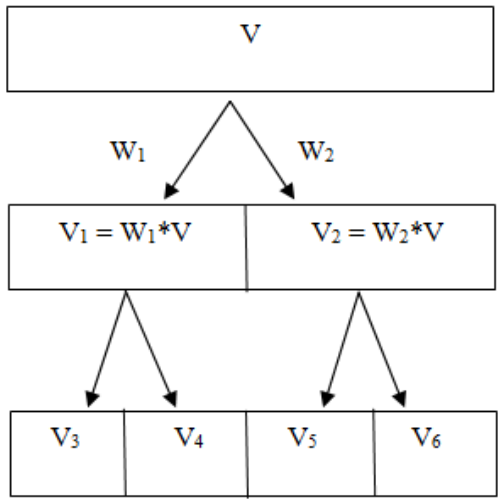

$$
W_{1}, W_{2}= \begin{cases}0 \text { and } 1 & \text { with probability } P(0 / 1) \\ 1 \text { and } 0 & \text { with probability } P(1 / 0) \\ W_{X / X} \text { and } 1-W_{X / X} & \text { with probability } P(X / X)\end{cases}
$$

where, $0<\mathrm{Wx} / \mathrm{x}<1$

Volume $=\mathrm{V}=\mathrm{V}_{1}+\mathrm{V}_{2}+\mathrm{V}_{3}+\mathrm{V}_{4}+\mathrm{V}_{5}$

$$
\mathrm{P}(0 / 1)+\mathrm{P}(1 / 0)+\mathrm{P}(\mathrm{x} / \mathrm{x})=1
$$

Fig. 1. Cascade process principle in one dimension. Between two cascade levels, each interval is divided into two halves. The volume in each half is obtained by multiplying the total interval mass by a weight Wi (after Olsson, 1998).

\section{HESSD}

$10,4709-4738,2013$

IDF-curves for tropical india by random cascade modeling

\section{A. Rana et al.}

\section{Title Page}

Abstract Introduction

Conclusions References

\section{Full Screen / Esc}

Printer-friendly Version

Interactive Discussion 


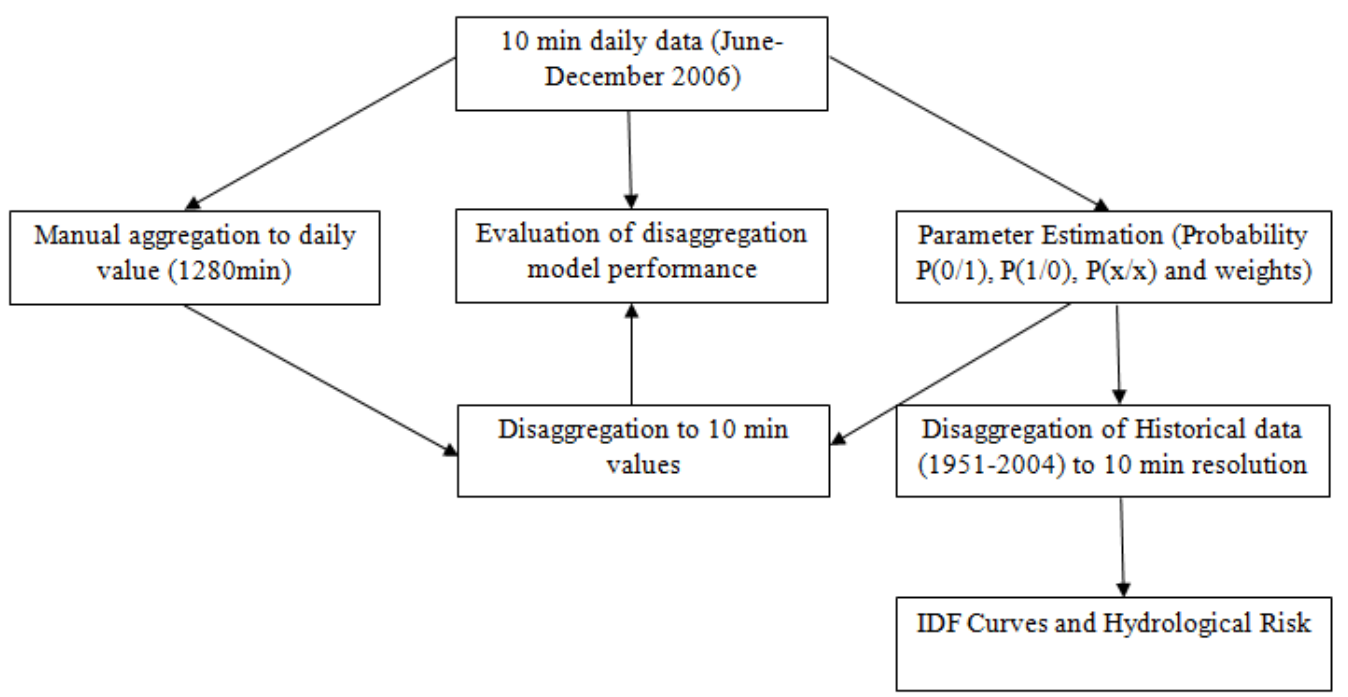

Fig. 2. Schematic representation of methodology adapted in the study.

\section{HESSD}

10, 4709-4738, 2013

IDF-curves for tropical india by random cascade modeling

\section{A. Rana et al.}

Title Page

\section{Full Screen / Esc}

Printer-friendly Version

Interactive Discussion 

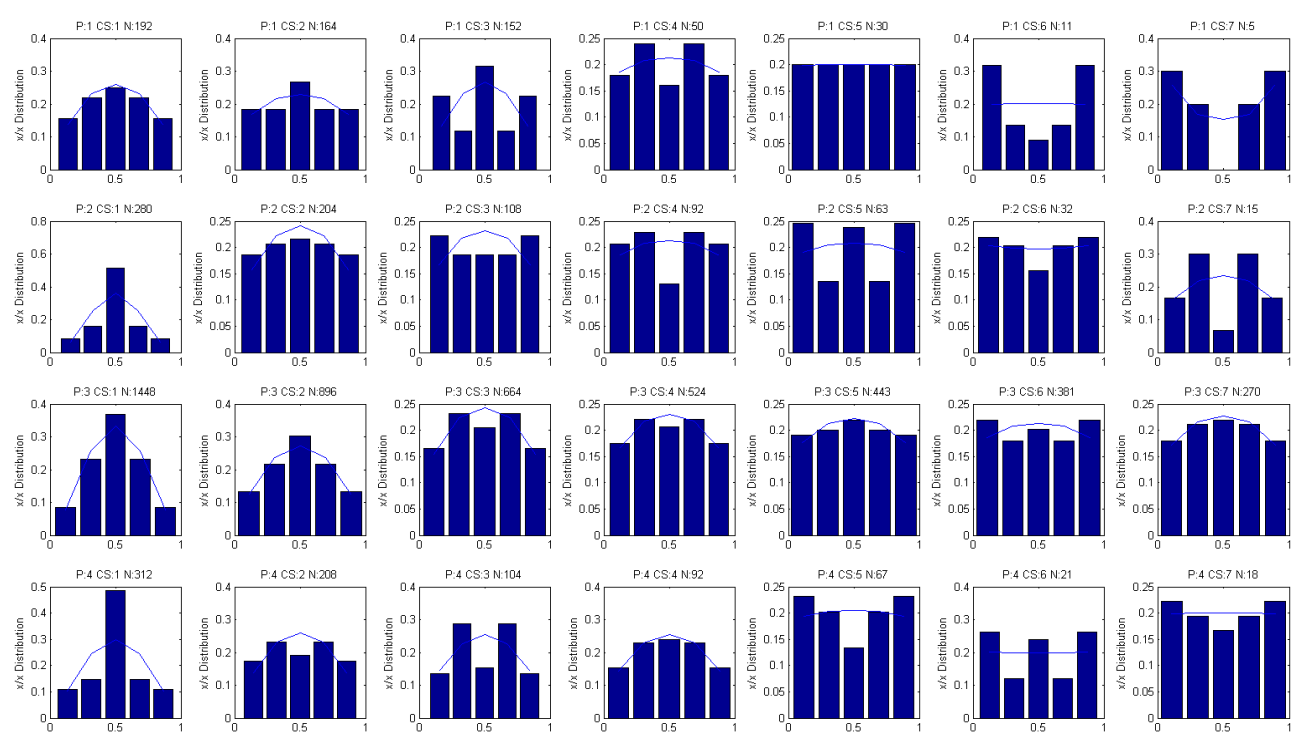

Fig. 3. Variation of empirical $\mathrm{x} / \mathrm{x}$-distribution with cascade step (bars) and fitted beta distribution (lines). In the diagram titles, $P$ denotes position type (1: isolated, 2: starting, 3: enclosed, 4: ending), cs denotes cascade step (step 1 represents the "cascading" from 1280 to $640 \mathrm{~min}$, step 2 from 640 to $320 \mathrm{~min}$, etc.), and $N$ denotes the total number of $\mathrm{x} / \mathrm{x}$-divisions for this position type and cascade step.

\section{HESSD}

10, 4709-4738, 2013

\section{IDF-curves for tropical india by random cascade modeling}

\section{A. Rana et al.}

\section{Title Page}

14

$\rightarrow$

4

$>$

Back

Close

Full Screen / Esc

Printer-friendly Version

Interactive Discussion 


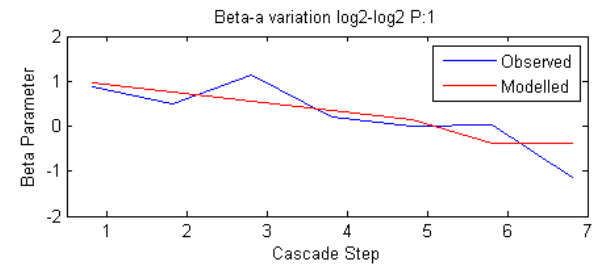

HESSD

10, 4709-4738, 2013

IDF-curves for tropical india by random cascade modeling

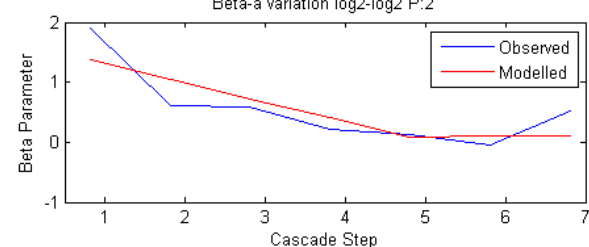

Beta-a variation $\log 2-\log 2 \mathrm{P}: 3$

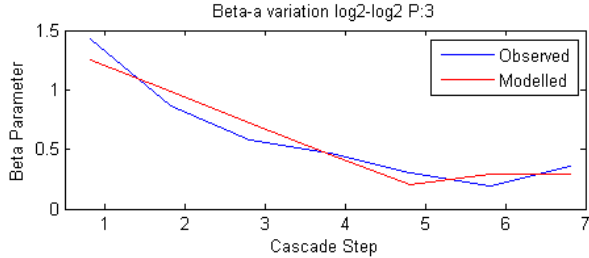

Beta-a variation $\log 2-\log 2 \mathrm{P}: 4$

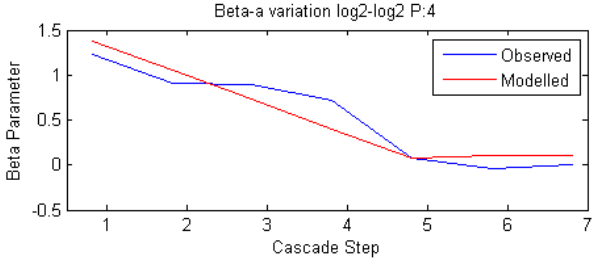

A. Rana et al.

Title Page

Abstract Introduction

Conclusions

References

Tables

Figures

14

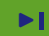

4

Back

Full Screen / Esc

Fig. 4. Variation of beta-parameter a with cascade step. In the diagram titles, $P$ denotes position type (1: isolated, 2: starting, 3: enclosed, 4: ending).

Printer-friendly Version

Interactive Discussion 

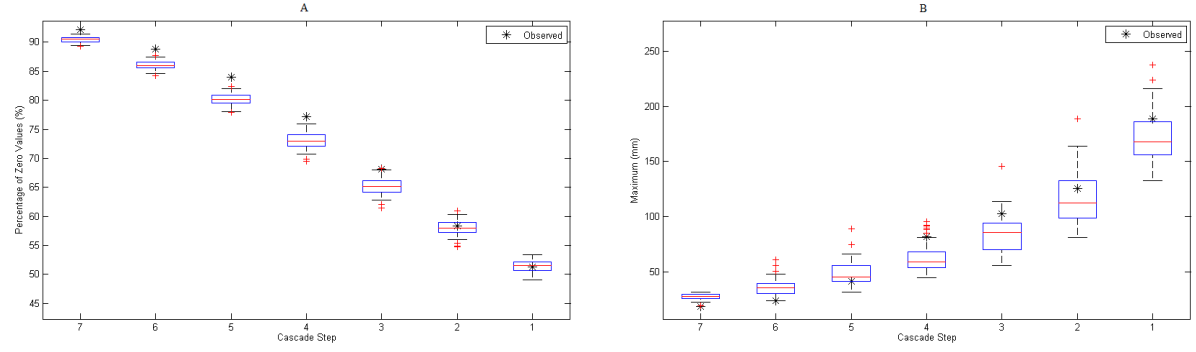

\section{IDF-curves for tropical india by random cascade modeling}

\section{A. Rana et al.}

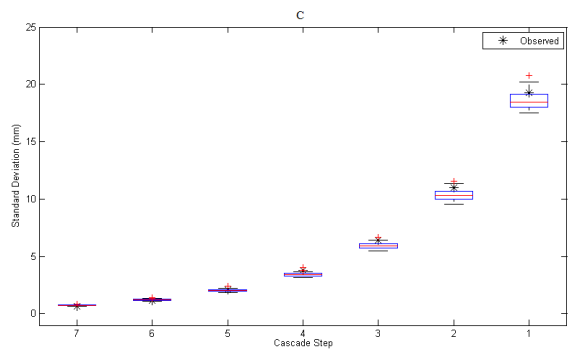

Title Page

Fig. 5. (A) Preservation of the generated intermittency Po across scales with $c s=7$ (10 $\mathrm{min})$ to $c s=0(1280 \mathrm{~min})$ (left to right i.e. Cascade step from $c s=7$ to $c s=0)$. (B) Preservation of the mean daily maximum and (C) Preservation of standard deviation in disaggregation for different cascade steps with observations. Bars give range of 1S.D. (left to right i.e. Cascade step from $c s=7$ to $c s=0$ ). (Blue box in the figure represents 25 th and 75 th percentiles with red line in middle as median; Red marks outside are outliers).

\section{4}

4

Back

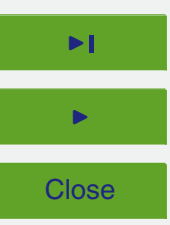

Full Screen / Esc

Printer-friendly Version

Interactive Discussion 

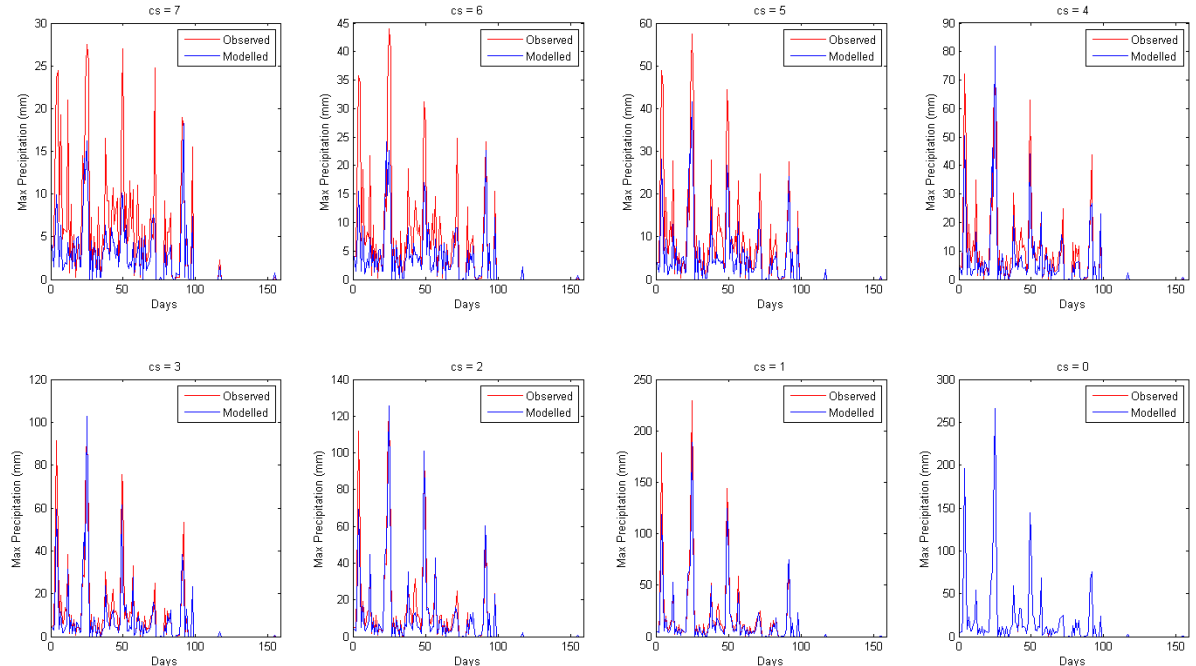

Fig. 6. Comparison of observed daily maximum values with generated daily maximum for each cascade step (Observed-Blue and Generated-red).

\section{HESSD}

10, 4709-4738, 2013

IDF-curves for tropical india by random cascade modeling

\section{A. Rana et al.}

\section{Title Page}

Abstract Introduction

Conclusions References

Tables Figures

14

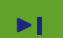

4

Back

Close

\section{Full Screen / Esc}

Printer-friendly Version

Interactive Discussion 


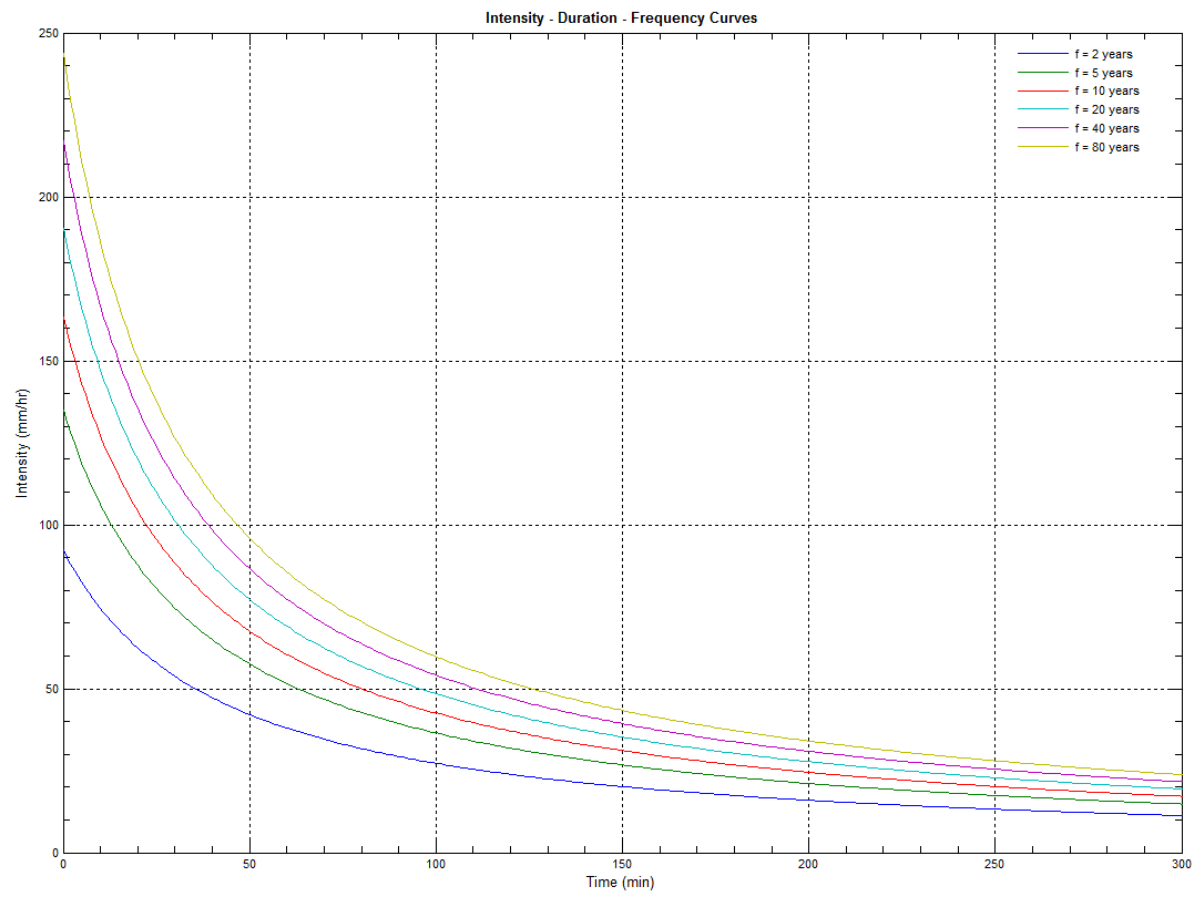

\section{HESSD}

10, 4709-4738, 2013

IDF-curves for tropical india by random cascade modeling
A. Rana et al.

Title Page

Fig. 7. Historical IDF curve for the city of Mumbai as represented by disaggregated data for period 1951-2004.

Full Screen / Esc

Printer-friendly Version

Interactive Discussion 